\title{
Velasco, Laura, Christian Zlolniski y Marie-Laure Coubès (2014), De jornaleros a colonos: residencia, trabajo e identidad en el Valle de San Quintín, Tijuana, El Colegio de la Frontera Norte, 406 p.
}

\author{
Patricia Arias*
}

Si a cada región la define un momento histórico, no cabe duda de que el norte de México es el resultado del siglo XX. La franja fronteriza con Estados Unidos empezó a recibir población desde los proyectos colonizadores, atribuibles en buena medida a la visión estratégica de Lázaro Cárdenas, de tal manera que poco a poco, y más tarde de manera explosiva, empezaron a destacar en la geografía fronteriza lugares apenas nombrados pero que al paso del tiempo y los acontecimientos se convirtieron en grandes y complejas ciudades como Tijuana, Ciudad Juárez y Nuevo Laredo. Pero también, desde la década de 1980, el norte ha sido el espacio donde empezaron a gestarse fenómenos urbanos inéditos en forma de asentamientos espontáneos cada vez más poblados y extensos como San Quintín, que es el tema de este libro recientemente publicado por El Colegio de la Frontera Norte.

Si el reto a principios del siglo XX fue cómo poblar ese espacio semidesértico tan cercano a Estados Unidos, el desafío un siglo después es cómo armonizar, encauzar, gestionar el crecimiento en un espacio heterogéneo, diverso y discontinuo como el Valle de San Quintín, donde han llegado sucesivas oleadas de migrantes, en especial indígenas, sobre todo del estado de Oaxaca.

Pero para gestionar hay que conocer. Y eso es lo que ofrece este estudio: la historia o, más bien dicho, la construcción social de ese espacio, como resultado de una investigación interdisciplinar de alrededor de 15 años que estuvo a cargo de tres investigadores: una socióloga, un antropólogo y una demógrafa. Gracias a ese diálogo y al trabajo en equipo, los autores elaboraron una propuesta metodológica que combinó métodos cuantitativos y cualitativos para abarcar y entender un espacio donde en 2010 vivían alrededor de cien mil habitantes, es decir, tanto o más poblado que ciudades como Ocotlán (Jalisco), Acayucan (Veracruz), y la conurbación MoroleónUriangato (Guanajuato).

\footnotetext{
* Universidad de Guadalajara. Dirección postal: Guanajuato 1045, col. Alcalde Barranquitas, 44260, Guadalajara, Jalisco, México. Correo electrónico: <mparias1983@gmail.com>.
} 
Y sin embargo, a diferencia de ellas, con recursos y atribuciones tan distintos, San Quintín carece de existencia político-administrativa, por lo tanto también de categoría censal, de manera que la investigación cuantitativa era particularmente complicada. Además de los ajustes que se hicieron para utilizar información del INEGI, la investigación recurrió a una encuesta retrospectiva: Encuesta Biográfica de Movilidad Residencial y de Empleo en San Quintín (Ebimre). Por su parte, el trabajo cualitativo se basó en varias técnicas: etnografía, entrevistas a profundidad, observación participante, historias de vida e intervención sociológica, que supusieron grupos focales, talleres y discusiones. Frente a un universo tan amplio, la investigación tuvo que concentrarse en tres colonias que fueron seleccionadas por su antigüedad, diferente origen étnico e inserción laboral de los pobladores.

La propuesta metodológica de este estudio puede resultar muy útil para otras investigaciones. Como sabemos, los mayores crecimientos demográficos de los últimos años corresponden a lugares que antes del año 2000 apenas tenían población -si es que existían-, por lo que la información acerca de su pasado, y sobre todo de su presente, suele ser muy deficiente. Por esa razón, el manejo de fuentes y la combinación de métodos que proponen Velasco, Zlolniski y Coubés pueden servir de hoja de ruta para el estudio de fenómenos similares que forman parte del crecimiento de los espacios metropolitanos en el México de hoy.

San Quintín, dicen los autores, es un ejemplo paradigmático de los fenómenos esperados -pero también inesperados-que ha desatado la economía agroexportadora que tanto se ha desarrollado en los estados del norte del país, debido en gran medida a la vecindad con Estados Unidos, principal consumidor de hortalizas y frutas frescas.

En la introducción y el capítulo I los autores ofrecen una síntesis de los ocho capítulos que integran el libro y que desarrollan a partir de tres ejes analíticos: el trabajo, la residencia y la identidad. En cada uno de ellos hay avances conceptuales, maneras nuevas de mirar y entender esos procesos que representan aportes fundamentales para la sociología del trabajo, la sociología urbana y desde luego el conocimiento de la región.

En primer lugar, el trabajo. Los autores hacen hincapié en el impacto que ha tenido la reestructuración productiva de la agricultura agroexportadora sobre el sistema de trabajo. Uno en especial: el desarrollo tecnológico en la agricultura modificó los ciclos estacionales de producción de las plantas; eso transformó los escenarios laborales, y muy pronto también de vida de los trabajadores que desde la década de 1970 habían comenzado a llegar al Valle como jornaleros temporales con la esperanza, el deseo y la intención de regresar a sus comunidades de origen en México. 
Hay que tener presente que los estudios, en especial las investigaciones antropológicas realizadas en las comunidades de origen, habían constatado que los campesinos, durante los tiempos de menos trabajo en sus parcelas, salían a laborar como jornaleros asalariados a las fincas de café, tabaco y frutas, a las plataformas petroleras, al comercio y a los servicios en diversas regiones del país. Con base en esa migración laboral temporal la gente del campo obtenía ingresos "complementarios", como se decía, que permitían dos cosas: por una parte, acceder a bienes que las producciones agrícolas de subsistencia no hacían posible y, dos, financiar y de esa manera mantener las tradiciones cívico-religiosas que garantizaban a los hombres el acceso al poder local. De esa manera, el jornalerismo temporal contribuía a la reproducción de la economía y las sociedades rurales. Con ese esquema-que, hay que decirlo, los propios jornaleros solían reiterar-se entendió durante mucho tiempo la migración laboral rural: se trataba, se insistía, de jornaleros temporales que cada año volvían a ser campesinos en sus comunidades de origen en México.

La tecnología rompió ese patrón migratorio cuando hizo posible la producción de frutas y hortalizas durante todo el año, ya no sólo en ciertas épocas y determinadas estaciones. Eso cambió todo porque las empresas agroexportadoras requirieron de trabajadores permanentes, no de jornaleros eventuales que se desplazaran de acuerdo con los calendarios laborales y festivos de sus comunidades de origen en México.

Así las cosas, como muestran los autores, el cambio tecnológico sentó las bases para la permanencia de los trabajadores en los lugares de trabajo, es decir, en las cercanías de las explotaciones agrícolas y lejos de sus lugares de origen. Al asentamiento de los jornaleros en el Valle de San Quintín, como en tantos otros lugares, contribuyeron, sin duda, la confluencia de dos procesos en los lugares de origen: por una parte, la pérdida de viabilidad de las economías agropecuarias de pequeña escala; por otra, los cambios en la propiedad agraria como consecuencia de la puesta en marcha de Procede (Programa de Certificación de Derechos Ejidales y Titulación de Solares) que, aunque otorgó la titularidad de las propiedades rurales, también significó la pérdida de la posibilidad de tener acceso a la tierra para muchos campesinos, en especial para los jóvenes que, sin derecho a la tierra, perdieron una de las razones más poderosas para el retorno recurrente a sus comunidades de origen.

Ambos procesos, lo sabemos, han sido muy documentados en los lugares de origen. Lo que aporta esta obra es justamente lo que faltaba: conocer cómo la agricultura de exportación suscitó la demanda de un nuevo tipo de trabajador: el jornalero como categoría laboral permanente. 
Eso representa una primera gran aportación del libro de Velasco, Zlolniski y Coubés a la sociología del trabajo. Porque lo que ellos demuestran es que en la actualidad las empresas agroexportadoras efectivamente requieren de trabajadores permanentes, pero en la mayoría de los casos en calidad de jornaleros durante todo el tiempo que duren sus trayectorias laborales. El jornalerismo ha dejado de ser una categoría laboral transitoria para convertirse en una forma de inserción laboral a largo plazo. Los jornaleros pueden cambiar de empresa o migrar a trabajar a otros lugares, pero en calidad de jornaleros no especializados con escasas posibilidades de movilidad laboral ascendente. Como documentan los autores, la posibilidad de que la especialización mejore las condiciones salariales en la horticultura crece de manera muy lenta en la región; más lenta aún para las mujeres y los indígenas. Y nuevas oleadas de migrantes llegan a ocupar los puestos no calificados que siguen en oferta. La movilidad, si es que se le puede llamar así, parece más viable fuera de los empleos agrícolas. Lo que encuentran los autores es que con el paso de las generaciones, las familias jornaleras tienden a salir de la agricultura para dedicarse a otras actividades, en especial en el sector terciario. Constatan también que la búsqueda de opciones de trabajo e ingresos ocurre en las colonias de San Quintín.

Y ese es otro de los hallazgos importantes de esta investigación en términos de sociología urbana: dar cuenta del proceso de asentamiento - de sedentarización lo llaman los autores- que significa la permanencia indefinida y a largo plazo de los jornaleros en los lugares de destino. Eso representa un gran cambio en la manera de entender la formación y la dinámica de los asentamientos relacionados con la agroindustria. A pesar de la insistencia todavía en algunos estudios, la evidencia de esta investigación resulta contundente: la eventualidad de que los jornaleros regresen a sus comunidades de origen ya no forma parte de los escenarios de vida de los vecinos de San Quintín, de la mayoría de ellos al menos. Como muestra la investigación, los jornaleros salieron de los campamentos que los alojaban en las cercanías de las empresas, pero no para regresar a sus comunidades en otros estados de México, sino para formar colonias que han dado lugar a un espacio fragmentado, disperso y desigual, pero residencial y urbano a fin de cuentas. Desde San Quintín, señalan, se generan incluso desplazamientos hacia diferentes lugares, incluidos Estados Unidos y Canadá, pero no de retorno a las comunidades de origen en México.

Como sabemos desde los estudios pioneros de sociología urbana de la Escuela de Chicago, las empresas, en momentos de auge, son extraordinariamente eficaces y exitosas para promover la llegada de trabajadores a los lugares donde los necesitan, por más alejados e inhóspitos que sean; pero eso 
mismo suele detonar condiciones de vida tan deplorables que terminan por movilizar a las iglesias, las organizaciones y el Estado, que, junto con los trabajadores, son los que a fin de cuentas tienen que asumir los costos del establecimiento, la residencia y la arquitectura social de los asentamientos. Resultan sobrecogedoras las imágenes de las casas redondas a las que llegaron a vivir los migrantes mexicanos atraídos a Chicago en los años veinte; o las de los campamentos donde se alojaban los oakies - los migrantes pobres de Oklahoma- en su éxodo hacia los valles de California en la década de 1930.

En San Quintín, como en Chicago y California, los jornaleros se convirtieron en pobladores, y es desde esa perspectiva que hay que entender -como se hace en este libro- la salida de los campamentos, los procesos de asentamiento, las demandas de vivienda y de servicios, los esfuerzos por comprar los lotes donde viven, las infinitas actividades económicas que desarrollan en las colonias, las luchas políticas, y las relaciones con las iglesias, las organizaciones no gubernamentales y sobre todo con el Estado, el cual a pesar de todas sus deficiencias e ineficiencias, ha jugado un papel central en la gestión -sobre todo reciente- de los asentamientos. La investigación documenta muy bien cómo en los últimos años el Estado ha incorporado a los vecinos de San Quintín a los programas sociales encaminados a atender a las poblaciones vulnerables.

La tercera aportación de esta obra tiene que ver con la identidad, tema de preocupación sociológica y antropológica desde hace años. Lo que muestra esta investigación es que los jornaleros, como trabajadores y colonos, a través de luchas, alianzas y conflictos han construido historia, relaciones, cronologías, identidad a fin de cuentas, que remiten a procesos locales de cambio laboral, residencial, familiar, de relaciones de género que han experimentado en San Quintín; no en esos lugares lejanos de los que un día salieron, aunque sean siempre añorados -e idealizados- por las memorias individuales y familiares. El caso de los triquis, que se presenta en el capítulo VIII, resulta ejemplar para conocer cómo los arreglos y acuerdos logrados en San Quintín pueden resultar tan distintos a aquellos con los que vivían o por los que se mataban en Oaxaca, su estado natal. Los triquis, afamados por la violencia de su vida comunitaria -situación que, entre otras cosas, los obligaba a migrar-, han recreado, pero también reinventado sus relaciones, tradiciones y fiestas como grupo étnico dejando de lado las filiaciones territoriales fragmentadas y partidistas que los dividían en Oaxaca para generar una organización independiente, que los cohesiona como grupo arraigado con intereses propios en San Quintín.

Después de leer el libro de Velasco, Zlolniski y Coubès no hay marcha atrás, no es posible repetir viejos argumentos porque lo que ellos muestran 
y demuestran es que lo que ha sucedido en el Valle de San Quintín hay que entenderlo y conceptualizarlo de nuevas maneras. En primer lugar, que los jornaleros agrícolas forman una categoría laboral permanente y a largo plazo, que es la que requiere y ha modelado el capital agroexportador. Los jornaleros no son gente del campo que sale a trabajar de manera temporal para regresar a un mundo social rural donde son agricultores, campesinos y ciudadanos con plenos derechos. En segundo lugar, que los jornaleros son residentes permanentes de los asentamientos que han creado y por los cuales han luchado, y donde construyen y consolidan sus proyectos personales y familiares. En tercer lugar, que las relaciones, alianzas, arreglos e identidad que han construido en las colonias no son una reproducción, una copia de la vida y las instituciones comunitarias de sus lugares de origen; hay matices, elementos y rasgos recreados, pero han sido resignificados para ayudarles a relacionarse en los asentamientos donde ahora conviven.

Para retomar lo dicho al principio, el ejemplo de San Quintín anuncia fenómenos y situaciones que veremos multiplicarse en el siglo XXI. El análisis que se hace de las luchas y los mecanismos de los que se han valido los vecinos de esa población para generar y gestionar su espacio representa un estudio pionero en la región, que resulta de consulta indispensable para analizar lo que está sucediendo en otros espacios del país que, como San Quintín, dan cuenta de la emergencia de una nueva geografía en México. Este libro es importante porque saca de la penumbra la presencia y trayectoria, las luchas y vicisitudes de espacios y pobladores que, aunque son muchos y están cada vez más organizados, permanecen en los márgenes del reconocimiento.

Los autores señalan un hecho escalofriante. En 2013 el gobernador de Baja California le negó al Valle de San Quintín el derecho a ser municipio, a pesar de sus cien mil habitantes. Esa cifra convierte al Valle en un territorio muy poblado y con mayores requerimientos de atención y de todo tipo de servicios que infinidad de municipios donde los migrantes eran ciudadanos de pleno derecho, pero de los que un día tuvieron que salir hacia espacios donde han tenido que comenzar a luchar por sus derechos desde la inexistencia legal y la invisibilidad política. 